
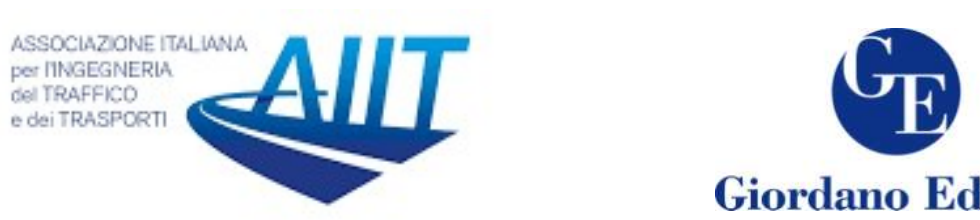

Giordano Editore

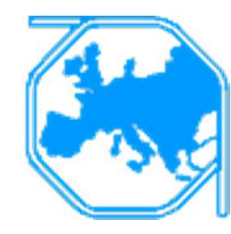

\title{
Understanding how drivers are injured in rear-end collisions
}

\author{
Essam Dabbour ${ }^{1 *}$, Abdallah Badran ${ }^{2}$ \\ ${ }^{1}$ Associate Professor, Abu Dhabi University, P.O. Box 59911, Abu Dhabi, United Arab Emirates \\ ${ }^{2}$ Graduate Student, Abu Dhabi University, P.O. Box 59911, Abu Dhabi, United Arab Emirates
}

\begin{abstract}
Rear-end collisions represent the most common type of collisions with more than 2.5 million rear-end collisions reported every year in the United States. Most of the previous research studies that identified risk factors related to the probability of injury in rear-end collisions were based on pooling data from few years (usually $2-4$ years) into a single dataset for analysis. This approach carries the risk of introducing aggregation bias in the analysis. Risk factors identified using that approach might have been significant at the time of the analysis, but their significance might change afterward due to the ongoing changes in vehicle technologies, driver behavior, traffic volumes, road conditions, law-enforcement technologies, and implemented policies. Thus, understanding the temporal stability trends of the factors influencing how drivers are injured in rear-end collisions would help researchers in evaluating the effectiveness of implementing different safety treatments so that researchers could understand whether any safety improvements, observed after applying a certain safety treatment, are attributed to the specific treatment or simply attributed to the temporal instability of the factors being addressed. This study investigates the temporal stability of the factors related to drivers' injuries in rear-end collisions. The research is based on utilizing logistic regression modelling to analyze all rear-end collisions that occurred in North Carolina from January 1, 2007 to December 31, 2013. A logistic regression model is developed for each year, and the models are compared together to identify the most temporally stable factors related to drivers' injuries in rear-end collisions. The findings of this research have the potential to help decision makers develop policies and countermeasures that improve roadway safety by focusing on risk factors that consistently increase the probability of injuries for drivers in rear-end collisions.
\end{abstract}

Keywords: Rear-end collisions; two-vehicle collisions; logistic regression.

\section{Introduction}

A rear-end collision occurs when the front of a vehicle collides with the rear of another vehicle travelling ahead of the first vehicle at the same direction (Wang and Abdel-Aty, 2006). Rear-end collisions represent the most frequent type of multi-vehicle collisions with more than 2.5 million rear-end collisions reported every year in the United States, comprising approximately one third of annual traffic collisions of all types in the United States (Shawky et al., 2017).

* Corresponding author: Essam Dabbour (edabbour@hotmail.com) 
Several research studies investigated the factors that increase the probability of injury in rear-end collisions. Shawky et al. (2017) investigated the factors affecting the occurrence and severity of rear-end collisions by using binary-logit modelling to analyze 1,841 police-reported rear-end collisions that occurred in Abu Dhabi (United Arab Emirates) for the period from 2010 to 2014. They found that drivers' injury severity in rear-end collisions increase on rural roads and when the driver exceeds the speed limit; while the severity decreases with the increase of the number of lanes, when the driver is local, and with the increase of the experience of the rear driver.

Yasmin et al. (2016) used an ordered probit fractional split approach to analyze injury severity of four types of collisions, including rear-end collisions by using collision data from multilane highway segments in Florida for the period from 2009 to 2011. They found that the severity of rear-end collisions increases with the increase in lane width. Surprisingly, they also found that the severity of rear-end collisions increases with the increase of the annual average daily traffic volume (AADT).

Chen et al. (2016) used a decision table/Naïve Bayes (DTNB) hybrid classifier to analyze the severity of 11,383 rear-end collisions that occurred in New Mexico from 2010 to 2011. They found that injury severity increases for influenced drivers, for those not using seatbelts, for motorcyclists, and for drivers struck by a heavy vehicle. They also found that severity may increase in good lighting conditions, which contradicts the findings by Khattak (2001). There are mixed conclusions from different research studies regarding the effect of lighting conditions on the severity of rear-end collisions. While some studies concluded that inferior lighting conditions may increase the severity of rearend collisions (e.g. Anarkooli and Hosseinlou, 2016; Chen et al., 2015; Duncan et al., 1998), other studies found that inferior lighting may decrease the severity of a collision due to the increased attention paid by drivers (e.g. Chen et al., 2016; Venkataraman et al., 2013; Zhu and Srinivasan, 2011). Similar contradictions are also found regarding the effect of weather on the severity of rear-end collisions. While some studies found that adverse weather conditions increase collision severity (e.g. Chen et al., 2015; Duncan et al., 1998; Jung et al., 2014), other studies found that drivers are more careful under adverse weather conditions; and therefore, collision severity is decreased (e.g. Chen et al., 2016; Haque et al., 2012; Milton et al., 2008; Savolainen and Mannering, 2007; Shaheed et al., 2013; Yu and Abdel-Aty, 2014).

Chen et al. (2015) used a hybrid method that combines multinomial logit modelling and Bayesian network methods to analyze driver injury severities in rear-end collisions based on accident data collected in New Mexico from 2010 to 2011. They found that driver's injury severity in rear-end collisions increase in urban areas, if the driver is influenced by alcohol, if the driver is a female, if heavy vehicles were involved, if the driver is not familiar with the roadway, if a motorcycle was involved, if there were more than two vehicles involved, if the roadway grade was steep, if the roadway is curved, and in windy weather conditions. on the other hand, they found that severity would decrease in proper lighting conditions, when the intersection is signalized, and when the driver is using seatbelt.

Khattak (2001) used ordered probit modelling to analyze the severity 3,912 rear-end collisions that occurred in North Carolina in 1994 and 1995. He analyzed the factors related to the "struck" (front) driver, and those related to the "striking" (rear) driver. He found that driver's injury severity is likely to increase when more than two vehicles are involved in a rear-end collision. He also found that driver's injury severity is likely to increase with the increase of the vehicle's age, in darkness conditions, when the struck 
driver is a female, with the increase of the roadway grade, and when the driver is struck by a large vehicle, while is decreases when the vehicle of the struck driver is large. He also found that severity decreases during peak hours. An interesting finding is that injury severity typically increases when the struck driver is older, and the striking driver is younger.

It should be noted that all the aforementioned-studies are based on pooling data from few years (usually $2-4$ years) into a single dataset for analysis. Aggregating data from different years into a single file carries the risk of introducing aggregation bias in the analysis. Risk factors identified by those prior research studies might have been significant at the time of the analysis, but their significance might change afterward due to the ongoing changes in vehicle technologies, driver behavior, traffic volumes, road conditions, law-enforcement technologies, and implemented policies. (Dabbour, 2017a; Dabbour, 2017b; Dabbour et al., 2017; Behnood and Mannering, 2015).

The purpose of this research study is to analyze the temporal trends of the factors that cause injuries to drivers in rear-end collisions. The research is based on using logistic regression modelling to analyze all rear-end collisions that occurred in North Carolina for the period from January 1, 2007 to December 31, 2013. A logistic regression model is developed for each year to identify significant risk factors that increase the probability of injuries for drivers in rear-end collisions. The developed year-based models are compared together to identify the most temporally stable risk factors. The findings of this research have the potential to help decision makers develop policies and countermeasures that improve roadway safety by focusing on risk factors that consistently increase the probability of injuries for drivers in rear-end collisions.

\section{Data collection and preparation}

Data records were obtained for all two-vehicle rear-end collisions that occurred in North Carolina from January 1, 2007 until December 31, 2013. The data records were obtained from the Highway Safety Information System (HSIS), which is managed by the University of North Carolina Highway Safety Research Centre under a contract with the Federal Highway Administration (FHWA, 2019). For each analysis year, the following data files were obtained:

- The first file (collision file) includes all factors related to the collision itself (e.g. date, hour, weather conditions, and the speed limit and roadway characteristics at the location of the collision); and

- The second file (vehicle file) includes factors related to each vehicle involved in the collision (e.g., vehicle make, vehicle year, location of the damage in the vehicle, number of occupants, estimated travel speed at time of the collision, whether seatbelts were properly used, and the age and gender of the driver).

To ensure data consistency and eliminate potential random effects of unobserved factors, the focus of this research is on analyzing only rear-end collisions with two vehicles involved, in each collision, where both vehicles are light-duty vehicles. Furthermore, the focus of this research is on analyzing only rear-end two-vehicle collisions where each vehicle was occupied by the driver only without any accompanying passengers. Based on the criteria, every record in the collision file, in each analysis year, is associated with two records from the vehicle file for the same year. Records from both files, for each analysis year, were compiled into one dataset that was used for the analysis. The case number was used to link the records together from both data files. 


\section{Methodology}

Logistic regression was used to analyze data for each analysis year and identify the most significant factors that increase the probability of injuries for drivers in rear-end collisions for that analysis year. Logistic regression is a generalized linear model that predicts the probability of the occurrence of an event by coding the event as a dichotomous outcome variable (McCullagh and Nelder, 1989). The dichotomous outcome variable may depend on several explanatory variables for fitting the data to a logit function in the form:

$$
f(z)=e^{\wedge} z /\left(\left(1+e^{\wedge} z\right)\right)
$$

where $z$ is a logit function that represents the total contribution of all the explanatory variables used in the model and $f(z)$ is a dichotomous outcome variable that is assumed to follow Bernoulli distribution. For this research, the dichotomous outcome variable represents the probability that a rear-end collision will result in an injury to the "struck" driver at the front vehicle, given that a rear-end collision has already occurred. Based on that, the variable $f(z)$ takes the value of " 1 " if the rear-end collision has resulted in any injury to the "struck" driver, or the value of " 0 " if the collision was property damage only (PDO). The logit function in the model has the following form:

$$
z=\beta_{0}+\beta_{1} x_{1}+\beta_{2} x_{2}+\beta_{3} x_{3}+\cdots+\beta_{k} x_{k}
$$

where $\beta_{0}$ is the intercept and $\left(\beta_{1}, \beta_{2}, \beta_{3}, \ldots, \beta_{k}\right)$ are the regression coefficients of the explanatory variables $\left(x_{1}, x_{2}, x_{3}, \ldots, x_{k}\right)$, respectively. The explanatory variables (risk factors) that were investigated include:

- Factors related to the "struck" driver at the front vehicle - including age, gender, impairment level, and the use of seatbelt;

- Factors related to the "striking" driver at the rear vehicle - including age, gender, impairment level, and whether exceeding the speed limit;

- Factors related to the "struck" vehicle - including its age and whether it is a passenger car or another light-duty vehicle (i.e. a pickup truck, a cargo van, a minivan, a van, or a sports-utility vehicle);

- Factors related to the "striking" vehicle - including its age and whether it is a passenger car or another light-duty vehicle; and

- Factors related to the lighting/environmental conditions - including whether the collision occurred in darkness condition, and whether the collision occurred during adverse weather conditions.

In most countries, the "striking" driver at the rear "striking" vehicle is usually considered to be the at-fault driver due to the failure to maintain an adequate stopping sight distance. Most common causes of the failure to maintain an adequate stopping sight distance are speeding, impairment, fatigue, following too closely (tailgating), or distracted attention by performing other activities while driving (e.g. eating or using mobile phone). For the purpose of this research, the "striking" vehicle is identified by having damage at its front area, while the "struck" vehicle is identified by having damage at its rear area. These identifications are based on the variable " $V$ _damage" in the vehicle file that describes the area of the vehicle that was damaged due to the rear-end collision. 


\section{Results and discussion}

Table 1 shows descriptive statistics of rear-end collisions when compared with all twovehicle collisions. During the seven-year analysis period, a total of 235,499 rear-end collisions occurred, with 5,824 of them resulted in at least a visible injury for one, or both, of the drivers. The remaining 229,675 collisions were either property-damage only (PDO) or resulted in minor non-visible injuries that did not need hospitalization. As shown in Table 1, non-injury rear-end collisions represent $45.4 \%$ of all non-injury two-vehicle collisions; while injury rear-end collisions represent only $20.7 \%$ of all injury two-vehicle collisions. Overall, rear-end collisions represent $44.1 \%$ of all two-vehicle collisions during the analysis period. Table 1 also shows that the number of rear-end collisions, both injury and non-injury, has increased from 32,053 in 2007 to 37,699 in 2013 (a significant increase of $17.6 \%$ ); while other two vehicle collisions have increased by only $3.2 \%$ during the same period. This significant increase in the number of rear-end collisions might be attributed to the increase in the improper use of mobile phones while driving, which distracts drivers, during that period.

Table 2 shows the coefficients (and standard errors) associated with the logistic regression models developed for each analysis year. As shown in the table, impaired drivers have the highest probability to consistently cause injuries for themselves as well as for other drivers in rear-end collisions. This finding is consistent with the findings of several research studies (see for example Dabbour 2017b; Behnood and Mannering, 2015; Behnood et al., 2014; Kim et al., 2013; Suriyawongpaisal et al., 2002). The increased probability for an impaired driver to be injured, or to cause an injury, in a rear-end collision is attributed to the fact that an impaired driver may not be able to take appropriate evasive measures (in terms of proper steering and/or braking or accelerating) that may reduce the severity of a rear-end collision, given that such a collision is inevitable.

Table 2 also shows that the probability for the struck driver to be injured in a rear-end collisions is significantly reduced if the driver was properly using a seatbelt. The effect of using seatbelt is consistently significant throughout all analysis years. This finding adds to the growing number of research studies with similar findings (see for example Chen et al., 2016; Chen et al., 2015; Dabbour, 2017b; Dabbour et al. 2017).

Table 1. Frequencies and percentages of rear-end collisions when compared to all twovehicle collisions.

\begin{tabular}{|c|c|c|c|c|c|c|}
\hline \multirow[b]{2}{*}{ Year } & \multicolumn{2}{|c|}{ Rear-End Collisions } & \multicolumn{2}{|c|}{$\begin{array}{l}\text { Other Two-Vehicle } \\
\text { Collisions }\end{array}$} & \multicolumn{2}{|c|}{$\begin{array}{l}\text { Percentage of Rear-End } \\
\text { Collisions } \\
\text { (b) }\end{array}$} \\
\hline & Injury $^{(\mathrm{a})}$ & Non-Injury & Injury $^{(a)}$ & Non-Injury & Injury $^{(\mathrm{a})}$ & Non-Injury \\
\hline 2007 & 821 & 31232 & 3587 & 39744 & $18.6 \%$ & $44.0 \%$ \\
\hline 2008 & 815 & 30045 & 3171 & 37717 & $20.4 \%$ & $44.3 \%$ \\
\hline 2009 & 810 & 30241 & 3111 & 37311 & $20.7 \%$ & $44.8 \%$ \\
\hline 2010 & 838 & 32887 & 3182 & 39477 & $20.8 \%$ & $45.4 \%$ \\
\hline 2011 & 832 & 33542 & 3143 & 39861 & $20.9 \%$ & $45.7 \%$ \\
\hline 2012 & 853 & 34884 & 3037 & 40081 & $21.9 \%$ & $46.5 \%$ \\
\hline 2013 & 855 & 36844 & 3135 & 41561 & $21.4 \%$ & $47.0 \%$ \\
\hline All Years & 5824 & 229675 & 22366 & 275752 & $20.7 \%$ & $45.4 \%$ \\
\hline
\end{tabular}

(a) At least one person was visibly injured.

(b) When compared with all two-vehicle collisions. 
Table 2. Coefficients (and standard errors) associated with logistic regression models

\begin{tabular}{|c|c|c|c|c|c|c|c|}
\hline Explanatory Variable & 2007 & 2008 & 2009 & 2010 & 2011 & 2012 & 2013 \\
\hline Adverse weather ${ }^{(a)}$ & $\mathrm{NS}^{(\mathrm{g})}$ & $\mathrm{NS}^{(\mathrm{g})}$ & $\begin{array}{c}0.2612 \\
(0.1327)\end{array}$ & $\begin{array}{c}0.3376 \\
(0.1615)\end{array}$ & $\mathrm{NS}^{(\mathrm{g})}$ & $\mathrm{NS}^{(\mathrm{g})}$ & $\mathrm{NS}^{(\mathrm{g})}$ \\
\hline Darkness ${ }^{(b)}$ & $\begin{array}{c}0.4731 \\
(0.1364)\end{array}$ & $\begin{array}{c}0.4278 \\
(0.1378)\end{array}$ & $\begin{array}{c}0.6492 \\
(0.1278)\end{array}$ & $\begin{array}{c}0.4031 \\
(0.1352)\end{array}$ & $\begin{array}{c}0.3967 \\
(0.1355)\end{array}$ & $\begin{array}{c}0.3267 \\
(0.1350)\end{array}$ & $\begin{array}{c}0.3268 \\
(0.1343)\end{array}$ \\
\hline $\begin{array}{l}\text { Age of the struck } \\
\text { driver }^{(\mathrm{c})}\end{array}$ & $\begin{array}{c}0.0111 \\
(0.0027)\end{array}$ & $\begin{array}{c}0.0179 \\
(0.0027)\end{array}$ & $\begin{array}{c}0.0154 \\
(0.0027)\end{array}$ & $\begin{array}{c}0.0090 \\
(0.0027)\end{array}$ & $\begin{array}{c}0.0117 \\
(0.0027)\end{array}$ & $\begin{array}{c}0.0179 \\
(0.0025)\end{array}$ & $\begin{array}{c}0.0146 \\
(0.0026)\end{array}$ \\
\hline $\begin{array}{l}\text { Gender of the struck } \\
\text { driver }^{(\mathrm{d})}\end{array}$ & $\begin{array}{c}0.2288 \\
(0.0974)\end{array}$ & $\begin{array}{c}0.3174 \\
(0.0969)\end{array}$ & $N S^{(g)}$ & $\begin{array}{c}0.3965 \\
(0.0948)\end{array}$ & $\begin{array}{c}0.3292 \\
(0.0955)\end{array}$ & $\begin{array}{c}0.2887 \\
(0.0922)\end{array}$ & $\begin{array}{c}0.2328 \\
(0.0931)\end{array}$ \\
\hline $\begin{array}{l}\text { Impairment of the } \\
\text { struck driver }^{(\mathrm{e})}\end{array}$ & $\begin{array}{l}1.0515 \\
(0.2287)\end{array}$ & $\begin{array}{l}1.2090 \\
(0.2229)\end{array}$ & $\begin{array}{c}1.5477 \\
(0.1827)\end{array}$ & $\begin{array}{c}1.1161 \\
(0.2290)\end{array}$ & $\begin{array}{c}1.2758 \\
(0.2341)\end{array}$ & $\begin{array}{c}1.4971 \\
(0.2046)\end{array}$ & $\begin{array}{c}1.7733 \\
(0.1844)\end{array}$ \\
\hline $\begin{array}{l}\text { Struck driver using } \\
\text { seatbelt }\end{array}$ & $\begin{array}{l}-1.1649 \\
(0.1378)\end{array}$ & $\begin{array}{l}-0.9340 \\
(0.1503)\end{array}$ & $\begin{array}{l}-1.1274 \\
(0.1410)\end{array}$ & $\begin{array}{l}-1.0447 \\
(0.1467)\end{array}$ & $\begin{array}{l}-0.8512 \\
(0.0632)\end{array}$ & $\begin{array}{l}-1.1486 \\
(0.0758)\end{array}$ & $\begin{array}{l}-1.0364 \\
(0.0785)\end{array}$ \\
\hline $\begin{array}{l}\text { Age of the struck } \\
\text { vehicle }^{(\mathrm{c})}\end{array}$ & $\begin{array}{c}0.0172 \\
(0.0060)\end{array}$ & $\begin{array}{c}0.0249 \\
(0.0040)\end{array}$ & $\begin{array}{c}0.0187 \\
(0.0057)\end{array}$ & $\begin{array}{c}0.0209 \\
(0.0053)\end{array}$ & $\begin{array}{c}0.0204 \\
(0.0044)\end{array}$ & $\begin{array}{c}0.0249 \\
(0.0039)\end{array}$ & $\begin{array}{c}0.0233 \\
(0.0045)\end{array}$ \\
\hline 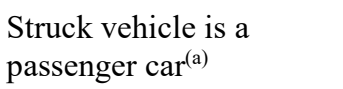 & $\begin{array}{c}0.2415 \\
(0.1000)\end{array}$ & $\begin{array}{c}0.3364 \\
(0.1019)\end{array}$ & $\begin{array}{c}0.3599 \\
(0.1017)\end{array}$ & $\begin{array}{c}0.3149 \\
(0.0984)\end{array}$ & $\begin{array}{c}0.3033 \\
(0.1006)\end{array}$ & $\begin{array}{c}0.2993 \\
(0.0975)\end{array}$ & $\begin{array}{c}0.3975 \\
(0.0991)\end{array}$ \\
\hline $\begin{array}{l}\text { Age of the striking } \\
\text { driver }^{(c)}\end{array}$ & $\begin{array}{c}0.0086 \\
(0.0029)\end{array}$ & $\begin{array}{c}0.0105 \\
(0.0030)\end{array}$ & $\mathrm{NS}^{(\mathrm{g})}$ & $\mathrm{NS}^{(\mathrm{g})}$ & $\mathrm{NS}^{(\mathrm{g})}$ & $\mathrm{NS}^{(\mathrm{g})}$ & $\mathrm{NS}^{(\mathrm{g})}$ \\
\hline $\begin{array}{l}\text { Gender of the striking } \\
\text { driver }^{(d)}\end{array}$ & $\mathrm{NS}^{(\mathrm{g})}$ & $\mathrm{NS}^{(\mathrm{g})}$ & $\mathrm{NS}^{(\mathrm{g})}$ & $\mathrm{NS}^{(\mathrm{g})}$ & $\mathrm{NS}^{(\mathrm{g})}$ & $\mathrm{NS}^{(\mathrm{g})}$ & $\mathrm{NS}^{(\mathrm{g})}$ \\
\hline $\begin{array}{l}\text { Impairment of the } \\
\text { striking driver }^{(\mathrm{e})}\end{array}$ & $\begin{array}{l}1.4326 \\
(0.2986)\end{array}$ & $\begin{array}{l}1.5503 \\
(0.3152)\end{array}$ & $\begin{array}{c}1.2241 \\
(0.3829)\end{array}$ & $\begin{array}{l}1.0888 \\
(0.3987)\end{array}$ & $\begin{array}{c}1.4791 \\
(0.3642)\end{array}$ & $\begin{array}{c}0.9131 \\
(0.4390)\end{array}$ & $\begin{array}{c}1.2855 \\
(0.4034)\end{array}$ \\
\hline $\begin{array}{l}\text { Striking driver was } \\
\text { speeding }^{(f)}\end{array}$ & $\begin{array}{c}0.7942 \\
(0.1604)\end{array}$ & $\begin{array}{c}0.6488 \\
(0.1696)\end{array}$ & $\begin{array}{c}0.8164 \\
(0.1556)\end{array}$ & $\begin{array}{c}0.5108 \\
(0.1653)\end{array}$ & $\begin{array}{c}0.4475 \\
(0.1756)\end{array}$ & $\begin{array}{c}0.4457 \\
(0.1096)\end{array}$ & $\begin{array}{c}0.4365 \\
(0.1137)\end{array}$ \\
\hline $\begin{array}{l}\text { Age of the striking } \\
\text { vehicle }^{(c)}\end{array}$ & $\mathrm{NS}^{(\mathrm{g})}$ & $\mathrm{NS}^{(\mathrm{g})}$ & $\mathrm{NS}^{(\mathrm{g})}$ & $\begin{array}{c}0.0140 \\
(0.0059)\end{array}$ & $\begin{array}{c}0.0113 \\
(0.0048)\end{array}$ & $\mathrm{NS}^{(\mathrm{g})}$ & $\begin{array}{c}0.0161 \\
(0.0045)\end{array}$ \\
\hline $\begin{array}{l}\text { Striking vehicle is a } \\
\text { passenger car }\end{array}$ & $\begin{array}{l}-0.1945 \\
(0.0955)\end{array}$ & $\begin{array}{l}-0.5691 \\
(0.0971)\end{array}$ & $\begin{array}{l}-0.4687 \\
(0.0962)\end{array}$ & $\begin{array}{c}-0.4508 \\
(0.0934)\end{array}$ & $\begin{array}{l}-0.3995 \\
(0.0947)\end{array}$ & $\begin{array}{l}-0.4617 \\
(0.0917)\end{array}$ & $\begin{array}{c}-0.4455 \\
(0.0929)\end{array}$ \\
\hline Intercept & $\begin{array}{l}-4.3402 \\
(0.2709)\end{array}$ & $\begin{array}{l}-4.9839 \\
(0.2713)\end{array}$ & $\begin{array}{l}-4.5375 \\
(0.2667)\end{array}$ & $\begin{array}{l}-4.7909 \\
(0.2879)\end{array}$ & $\begin{array}{l}-5.4705 \\
(0.2453)\end{array}$ & $\begin{array}{l}-5.4002 \\
(0.2353)\end{array}$ & $\begin{array}{l}-5.6507 \\
(0.2378)\end{array}$ \\
\hline Chi-square of the model & 145.5982 & 246.8439 & 279.1199 & 185.0881 & 142.0514 & 177.4758 & 207.2302 \\
\hline Number of observations & 31,908 & 30,731 & 30,947 & 33,604 & 34,213 & 35,634 & 37,596 \\
\hline
\end{tabular}

(a) Clear or cloudy weather is the reference category.

(b) Daylight or lighted road is the reference category.

(c) Continuous variable.

(d) Male driver is the reference category.

(e) Unimpaired driver is the reference category.

(f) Driving at, or below, the speed limit is the reference category.

(g) Not significant at 0.05 significance level.

Exceeding the speed limit by the striking driver is another factor that consistently increases the probability of injury in rear-end collision. This is explained by the increased impact when the striking driver is speeding. Exceeding the speed limit also reduces the perception-reaction time available for the striking driver, which allows less time for that driver to take any actions necessary to reduce the severity of a rear-end collision (such as steering, accelerating, or braking) given that such a collision is inevitable (Dabbour et al. 2019).

The age of the struck vehicle is a significant factor that consistently increases the probability of injury in rear-end collisions. For example, the coefficient associated with 
this factor in 2013 is 0.0233 , which implies that the probability of the struck driver to be injured in a rear-end collision increases by $1.898 \%-2.819 \%$ (odds ratio $1.01898-$ 1.02819 ) for each year increase of the age of his/her vehicle. For example, an 11-yearsold vehicle increases the probability of its driver's to be injured by $18.98 \%-28.19 \%$ when compared with a one-year-old vehicle. This finding may be explained by the ongoing improvements in vehicle safety features. Several studies found that modern vehicles are typically associated with reduced severity of drivers' injuries in singlevehicle collisions (see for example Dabbour 2017b; Behnood and Mannering, 2015; Behnood et al., 2014; Kim et al., 2013). The finding of this research study implies that modern vehicles are also associated with reduced severity of drivers' injuries in rear-end collisions. However, as shown in Table 2, the age of the striking vehicle is not a significant factor associated with the severity of a rear-end collision.

The ageing of the struck driver is a significant factor that increases the probability of being injured throughout all analysis years. This could be explained by the deteriorated health conditions that make the driver more susceptible to injuries. Furthermore, Table 2 shows that female drivers are more probable to be injured when compared to their male counterparts. This finding may also be explained by the difference in body size and structure (Dabbour et al., 2017; Haleem and Gan, 2015; Zhao and Khattak, 2015). However, the age and gender of the striking driver are not significant factors related to the severity of a rear-end collision.

The type of the struck vehicle is a significant factor related to the probability of injury for its driver, where passenger cars are typically associated with an increased probability of injury when compared to other light-duty vehicles (i.e. pickup trucks, cargo vans, minivans, vans, or sports-utility vehicles). Table 2 also shows that other light-duty vehicles (pickup trucks, cargo vans, mini-vans, vans, or sports-utility vehicles) cause more injuries when striking passenger cars in rear-end collisions. These two findings could be explained by the large mass of other light-duty vehicles (pickup trucks, cargo vans, mini-vans, vans, or sports-utility vehicles) when compared to passenger cars so that they provide more protection to their drivers, while causing more injuries to other drivers in the case of a rear-end collision.

Darkness is a significant factor that consistently increases the probability of injury in rear-end collisions. This finding could be explained by the fact that darkness usually reduces driver's ability to take appropriate evasive measures (in terms of proper steering and/or braking or accelerating) that may reduce the severity of a rear-end collision, given that such a collision is inevitable. This finding is also consistent with the findings of other research studies (see for example Zhao and Khattak, 2015; Kim et al., 2013; Abdel-Aty, 2003). In contrast, weather conditions were found to have no significant effect on the probability of injury in rear-end collisions. This finding might explain previous contradictory findings regarding the effect of weather on the severity of rear-end collisions, where some studies found that adverse weather conditions increase collision severity (e.g. Chen et al., 2015; Duncan et al., 1998; Jung et al., 2014) while other studies found that collision severity is decreased in adverse weather (e.g. Chen et al., 2016; Haque et al., 2012; Milton et al., 2008; Savolainen and Mannering, 2007; Shaheed et al., 2013; Yu and Abdel-Aty, 2014).

\section{Conclusions}

This paper investigated the factors that increase the probability of injury for drivers in rear-end collisions by analyzing all rear-end collisions that occurred in North Carolina 
during the period from January 1, 2007 to December 31, 2013. A logistic regression model was developed for each analysis year, and the models were compared together to identify the most temporally stable factors that increase the probability of injury in rearend collisions. Some of the findings are obvious and consistent with those found in previous research studies. Those findings include the effects of speeding, impaired driving, and the failure to use seatbelt by the struck driver. Some other findings are novel, such as the effect of the age of the struck vehicle, the age and gender of the struck driver, and the type of both the striking and struck vehicles. It was also found that darkness conditions significantly increase the probability of injury in rear-end collisions, while weather conditions have no significant effect. The gender of the striking driver was also found to have no significant effect on the probability of injury in rear-end collisions. The findings of this study can help decision makers allocate proper resources to improve awareness programs and licensing procedures that target driver groups that impose a higher risk on other drivers in rear-end collisions.

\section{References}

Abdel-Aty, M. (2003). Analysis of driver injury severity levels at multiple locations using ordered probit models. Journal of Safety Research, 34: 597 - 603.

Anarkooli, A.; and Hosseinlou, M. (2016). Analysis of the injury severity of crashes by considering different lighting conditions on two-lane rural roads. Journal of Safety Research, 56: $57-65$.

Behnood, A.; and Mannering, F. (2015). The temporal stability of factors affecting driverinjury severities in single-vehicle crashes: some empirical evidence. Analytic Methods in Accident Research, 8: 7 - 32.

Behnood, A.; Roshandeh, A.; and Mannering, F. (2014). Latent class analysis of the effects of age, gender, and alcohol consumption on driver-injury severities. Analytic Methods in Accident Research, 3(4): 56 - 91.

Chen, C.; Zhang, G.; Tarefder, R.; Ma, J.; Wei, H.; and Guan, H. (2015). A multinomial logit model-Bayesian network hybrid approach for driver injury severity analyses in rear-end crashes. Accident Analysis \& Prevention, 80: 76 - 88.

Chen, C.; Guohui Zhang, G.; Yang, J.; Milton, J.; and Alcántara, A. (2016). An explanatory analysis of driver injury severity in rear-end crashes using a decision table/Naïve Bayes (DTNB) hybrid classifier. Accident Analysis \& Prevention, 90: 95 $-107$.

Dabbour, E.; Haider, M.; Easa, S.; and Philip, T. (2019). Investigating temporal stability of risk externalities in traffic collisions. Journal of Transportation Safety \& Security (https://doi.org/10.1080/19439962.2019.1583706).

Dabbour, E. (2017a). Analyzing temporal trends of the factors that increase the risk of rollover in single-vehicle collisions. Journal of Transportation Safety \& Security. http://dx.doi.org/10.1080/19439962.2017.1337055.

Dabbour, E. (2017b). Investigating temporal trends in the explanatory variables related to the severity of drivers' injuries in single-vehicle collisions". Journal of Traffic \& Transportation Engineering, 4(1): $71-79$.

Dabbour, E.; Easa, S.; and Haider, M. (2017). Using fixed-parameter and randomparameter ordered regression models to identify significant factors that affect the 
severity of drivers' injuries in vehicle-train collisions. Accident Analysis \& Prevention, 107: $20-30$.

Duncan, C.; Khattak, A.; and Council, F. (1998). Applying the ordered probit model to injury severity in truck-passenger car rear-end collisions. Transportation Research Record, 1635(1): $63-71$.

Federal Highway Administration (FHWA) (2019). Highway Safety Information System (HSIS) Database. Available online at $<$ http://www.hsisinfo.org/ $>$ (date accessed: November 1, 2019).

Haleem, K.; and Gan, A. (2015). Contributing factors of crash injury severity at public highway railroad grade crossings in the US. Journal of Safety Research, 53: $23-29$.

Haque, M.; Chin, H; and Debnath, A. (2012). An investigation on multi-vehicle motorcycle crashes using log-linear models. Safety Science, 50: $352-362$.

Jung, S.; Jang, K.; Yoon, Y.; and Kang, S. (2014). Contributing factors to vehicle to vehicle crash frequency and severity under rainfall. Journal of Safety Research, 50: 1 10 .

Khattak, A. (2001). Injury Severity in Multivehicle Rear-End Crashes. Transportation Research Record, 1746: 59 - 68.

Kim, J.; Ulfarsson, G.; Kim, S.; and Shankar, V. (2013). Driver-injury severity in singlevehicle crashes in California: A mixed logit analysis of heterogeneity due to age and gender. Accident Analysis and Prevention, 50: 1073 - 1081.

McCullagh, P.; and Nelder, J. (1989). Generalized linear models, $2^{\text {nd }}$ Ed. Chapman and Hall, USA.

Milton, J.; Shankar, V.; and Mannering, F. (2008). Highway accident severities and the mixed logit model: an exploratory empirical analysis. Accident Analysis and Prevention, 40: 260 - 266.

Savolainen, P.; and Mannering, F. (2007). Probabilistic models of motorcyclists' injury severities in single- and multi-vehicle crashes. Accident Analysis and Prevention, 39: $955-963$.

Shaheed, M.; Gkritza, K.; Zhang, W.; and Hans, Z. (2013). A mixed logit analysis of twovehicle crash severities involving a motorcycle. Accident Analysis and Prevention, 61: $119-128$.

Shawky, M.; Kishta, M.; and Al-Harthi, H. (2017). Investigating Factors Affecting the Occurrence and Severity of Rear-End Crashes. Transportation Research Procedia, 25: $2098-2107$.

Suriyawongpaisal, P.; Plitapolkarnpim, A.; and Tawonwanchai, A. (2002). Application of 0.05 percent legal blood alcohol limits to traffic injury control in Bangkok. Journal of the Medical Association of Thailand, 85(4): 496 - 501.

Venkataraman, N.; Ulfarsson, G.; and Shankar, V. (2013). Random parameter models of interstate crash frequencies by severity, number of vehicles involved, collision and location type. Accident Analysis and Prevention, 59: 309 - 318.

Wang, X.; and Abdel-Aty, M. (2006). Temporal and spatial analyses of rear-end crashes at signalized intersections. Accident Analysis and Prevention, 38: $1137-1150$.

Yasmin, S.; Eluru, N.; Lee, J.; and Abdel-Aty, M. (2016). An Ordered Fractional Split Approach for Aggregate Injury Severity Modeling. Transportation Research Record, 2583: $119-126$.

Yu, R.; and Abdel-Aty, M. (2014). Analyzing crash injury severity for a mountainous freeway incorporating real-time traffic and weather data. Safety Science, 63: 50 - 56. 
Zhao, S.; and Khattak, A. (2015). Motor vehicle drivers' injuries in train-motor vehicle crashes. Accident Analysis and Prevention, 74: 162 - 168.

Zhu, X.; and Srinivasan, S. (2011). A comprehensive analysis of factors influencing the injury severity of large-truck crashes. Accident Analysis and Prevention, 43(1): 49 57.

\section{Acknowledgements}

The authors of this paper would also like to thank the staff at the Highway Safety Information System (HSIS) for providing the statistical data used in this research. 